\title{
Aumento da periodicidade dos Arquivos Brasileiros de Ciências da Saúde
}

Ricardo Peres do Souto ${ }^{1}$

A mudança do título da revista para Arquivos Brasileiros de Ciências da Saúde no início de 2008 (volume 33, número 1) transcorreu com êxito. A iniciativa foi apoiada por profissionais de saúde e a comunidade científica do Grande ABC. Recebemos também incentivo de instituições de outras regiões do país. O novo título já se encontra regularmente indexado no LILACS, mantendo um vínculo de continuidade aos Arquivos Médicos do ABC, e foi cadastrado no Instituto Brasileiro de Informação em Ciência e Tecnologia, recebendo código ISSN $1983-2451$.

Apesar da mudança de título ser uma das medidas de maior impacto, a reformulação da revista não pára nessa iniciativa. Pretendendo tornar-se uma alternativa real e atraente aos pesquisadores brasileiros na área de Ciências da Saúde, a revista também planejou o aumento de sua periodicidade de semestral para quadrimestral, reduzindo o intervalo entre a aprovação dos artigos e a sua divulgação. Este fascículo, referente ao período de maio a agosto, reafirma o compromisso com a nova periodicidade.

Acreditamos que os ajustes na política editorial da revista realizados nos últimos anos já estão produzindo frutos, como por exemplo, o aumento de artigos submetidos, particularmente de grupos de pesquisa externos à Faculdade de Medicina do ABC. Sendo mantido o atual ritmo, projetamos fechar o ano de 2008 com um número total de submissões pelo menos 30\% maior em comparação ao ano anterior.

Neste fascículo dos Arquivos Brasileiros de Ciências da Saúde:

- Castro et al. (página 70) estudam o perfil clínico de indivíduos acometidos por pneumonia adquirida na comunidade (PAC), com idade superior a 50 anos, no município de São Caetano do Sul. A PAC é uma condição de alta prevalência, particularmente importante como causa de morbimortalidade em idosos e, no entanto, nota-se uma escassez de trabalhos científicos explorando esse tema. As constatações dos autores são de interesse dos profissionais de saúde que podem ter contato com idosos;

- Rodrigues et al. (página 74) apresentam, de forma descritiva, a qualidade de vida, a sintomatologia depressiva e capacidade física de pacientes em fase pré e pós-transplante de fígado. Apesar de se tratar de estudo preliminar, com amostra pequena e originária de um mesmo centro, a iniciativa de identificar os sintomas que possam interferir na evolução do quadro clínico desses indivíduos transplantados, é sem dúvida, uma forma de contribuir para o estabelecimento de um consenso clínico e também de programas preventivos visando o bem-estar do paciente;

- Silva, Bittencourt e Sakae (página 79) discutem um método clínico de diagnóstico da anemia, cujo mérito é a sua extrema simplicidade. Conforme esperado, existe grande dificuldade de "calibrar" as impressões de diferentes observadores e tornar objetiva uma análise baseada na percepção pessoal. Mesmo assim, essa metodologia deve continuar a ser investigada e aperfeiçoada pela sua grande potencialidade como ferramenta para uma inspeção rápida da condição de saúde do paciente.

- Person, Tanaka e Iwamoto (página 83) relatam um caso de otite com complicação de infecção de meninges e evolução fatal. O artigo alerta para potencialidade de evolução ruim de uma doença comum, principalmente se não tratada adequadamente no início, como ocorreu no episódio. Da mesma forma, alerta para a etiologia do Streptococcus pyogenes, que, dependendo da cepa, deixa de ser uma infecção banal, transformando-se em potencialmente letal.

Ao final, a revista traz os anais do $33^{\circ}$ Congresso Médico Universitário do ABC (COMUABC), que será realizado na Faculdade de Medicina do ABC, entre 18 e 23 de agosto de 2008. São 84 resumos de apresentações orais e 88 pôsteres apresentando a produção científica discente dessa instituição. 